\title{
Ten Years of the Postdigital in the 52group: Reflections and Developments 2009-2019
}

Dave Cormier, University of Windsor, Windsor, Canada, dave@edactive.ca, Petar Jandrić, Zagreb University of Applied Sciences, Zagreb, Croatia, pjandric@tvz.hr, Mark Childs, Open

University, Milton Keynes, UK, mark.childs@open.ac.uk, Richard Hall, De Montfort University, Leicester, UK, rhall1@dmu.ac.uk, David White, University of the Arts London,

London, UK, david.white@ arts.ac.uk, Lawrie Phipps, Jisc, London, UK, Lawrie.Phipps@Jisc.ac.uk, Ian Truelove, Leeds Beckett University, Leeds, UK, i.a.truelove@leedsbeckett.ac.uk, Sarah Hayes, University of Wolverhampton, Wolverhampton, UK, Sarah.Hayes@ wlv.ac.uk, Tim Fawns, University of Edinburgh, Edinburgh, UK, T.Fawns@ed.ac.uk

\begin{abstract}
This paper traces ten years of development of the concept of the postdigital in the works of six academics (Richard Hall, Ian Truelove, David White, Mark Childs, David Cormier, and Lawrie Phipps) acting under the collective pseudonym the 52group. The first part of the paper reproduces the 52group's manifesto entitled 'Preparing for the postdigital era'. The second part of the paper reproduces 2015 responses to 'Preparing for the postdigital era' published on group members' blogs and websites. The third part of the paper brings together group members' responses written in 2019 for the purpose of this article. The conclusion analyses these developments and situates them within recent developments in postdigital thinking. The article provides deep insights into the nature of our postdigital reality and offers two main contributions. First, the article offers some intellectual ancestry for postdigital theory and practice. Second, the article offers a unique insight into the evolution of feelings of people who have thought deeply about our postdigital era. With these contributions, the article offers a much-needed historical view to the postdigital and situates current postdigital thought into wider philosophical, social, and educational contexts.
\end{abstract}

Keywords: postdigital, 52group, collective, posthumanism, evolution, algorithm

\section{Introduction (Dave Cormier and Petar Jandrić)}

In June 2009, during a two-day brainstorming public event, Richard Hall, Ian Truelove, David White, Mark Childs, David Cormier, and Lawrie Phipps produced a position paper 'Preparing for the postdigital era' (52group 2009) under the collective pseudonym 'the 52group'. While the paper was initially 'met with a mixture of scepticism and confusion', the term postdigital has slowly but surely started to appear in various contexts. In 2015, members of the 52group have publicly reflected to their 2009 position paper on their blogs and websites. In 2019, Gordon Asher emailed links to the 2009 position paper and 2015 reflections to Petar Jandrić. Delighted by this rare opportunity to examine eleven years of development of the concept of the postdigital, Petar contacted Dave Cormier and asked him to contact the original 52group members with a request to revisit the theme in 2019.

The first part of this paper reproduces the original text of 'Preparing for the postdigital era' (52group 2009). The second part of this paper reproduces 2015 responses to 'Preparing for the postdigital era' published on group members' blogs and websites. The third part of the paper brings together group members' responses written in 2019 - some of these responses have also been published on various blogs and websites, while others were collected by e- 
mail. Texts reproduced in this article have been lightly edited for style and clarity ${ }^{1}$. Texts and authorship $^{2}$ are lined up in chronological order. Based on this archive, the conclusion analyses early developments of the concept of the postdigital and situates them within a recent body of literature (Jandrić et al. 2018; Arndt et al. 2019; Fawns 2019; Ford 2019: Sinclair and Hayes 2019; etc.). Due to the impossibility of anonymising contributions, the draft article has undergone open peer review. Reviewers' comments are published as integral parts of the article, and reviewers have also become its co-authors.

\section{Preparing for the postdigital era - Version 0.1 June 17th, 2009 (52group 2009) ${ }^{3}$}

'We are stuck with technology when what we really want is just stuff that works.'

Douglas Adams

In an attempt to negotiate a shared language and vision for future work/projects building on the Open Habitat project ${ }^{4}$ we found ourselves establishing a common frame of reference. This is a first move towards trying to shift our thinking away from the simple digital/analogue distinction of technology towards a less divisive and more nuanced context for work; a human context that focuses on the essence of our work rather than the appearance. This concept paper is the record of two days of discussion at Cumberland Lodge.

$* * * * * * * * * * * * * * * * * * * * * * * * * * * * * * * * * * * * * * *$

The intersection of technology and the social has often been a driver of social change. The mainstreaming and mass production of powerful digital tools has had a profound effect on the way that we live and learn. These digital tools have allowed us to speed up communication, publish our thoughts in any number of ways and allowed for new complex forms of collaboration. The speed and reach of this transition has had a profound effect on what it means to be a participant in society. The speed of the change, however, has left us with the

1 Editing included turning hyperlinks into standard academic references (which has unfortunately somewhat changed the original 'feel' of the text). Following Postdigital Science and Education house style, various spellings such as 'Postdigital', 'post-digital' and 'post digital' have been standardized to 'postdigital' everywhere except in conferences names and publication titles.

2 'Preparing for the postdigital era' (52group 2009) was collectively written by members of the 52group and published without established order of authorship.

${ }^{3}$ The text was published online with the following footnote: '52group. This is a draft. it will change over the next few weeks and will be expanded. It should be seen as a public presentation of 2 days of brainstorming rather than a published document. Special thanks to Nancy White for her excellent advice.' The draft has never been changed or expanded.

${ }^{4}$ The JISC-funded Open Habitat project was a collaboration between the University of Oxford, Leeds Metropolitan University, King's College London, the University of Essex and Dave Cormier, based in Prince Edward Island. It took an innovative approach to encouraging creative online collaboration in Multi-User Virtual Environments (MUVEs) - the online 3D spaces in which each user is represented by an 'avatar' or 3D character. http://www.tall.ox.ac.uk/research/past/habitat.php. 
mistaken belief that social change was somehow 'created' by the digital rather than simply played out on the canvas of the digital; that the digital itself is the main driver of change. We would argue the opposite. This ontological error has had us move towards placing technology at the forefront (think e-learning as distance learning) and moving our focus away from the people involved in these processes; the needs that they have and the skills that they bring.

Not only is the digital subservient to the social, it is, in some ways (and soon most ways), transparent. We are moving towards a postdigital age where the tools driven by the microprocessor are common to the extent to which they will no longer be noticed. As the 'digital' calculator and the 'digital' watch have become calculators and watches, so will the ebook become a book and IM become 'message': the 'instant' will be taken for granted. Things digital will be accepted alongside our other technologies and the slate swept clear of many of the distracting dualisms (and technological factions) that pervade the educational discourse. The postdigital frees us to think more clearly and precisely about the issues we face, rather than become tied to an obsession with, and the language of, the new. It allows is to take a broader approach to the challenges and opportunities we face. Removing the focus on the digital leads us to see the division between the 'digital' have and have-nots not in terms of their lack of access to digital technology, but in terms of their lack of access to economic, social and political power.

Discourse in the area of social innovation has been dominated in recent years with the interminable discussion of the next new 'digital technology' to take over the internet space, a resolution of which does not seem to be (and probably can not be) forthcoming. We would argue that this is because the digital era is fading away, causing the stagnation of the digital discourse. The question of 'the next new technology' (meaning digital) is really only of interest to venture capitalists and pundits looking to secure their future funding. The social experiences that are encapsulated by (at the time of writing) microblogging may continue on the inside of that particular space or move to another, but they are experiences that while supported by a certain technology are no more about 'the technological' than the telephone. These technologies enable, they do not create. Their power, therefore, arises in the act of their colonisation, or appropriation, by people into their lives; when they cease to be technology and become simply 'stuff that works'. This move is the result of the critical shift implied by the second wave of adopters of 'digital technologies'. As digital technology is culturally normalised it becomes ever more transparent. For example, our mobile phone becomes an extension of ourselves, just as the pen and the book did in their turn. The concept of the postdigital is not a rejection of the difficulties presented in reducing barriers for adoption, but rather a realisation that the focus on the digital as 'other' creates a higher barrier, a presumed anticipation of difference which makes it more difficult for the newcomer to normalise to the new.

The transition to a postdigital way of thinking allows for that previously coded as 'digital' to be woven into the wider discussion of social dialects that people bring to their acts of collaboration. One of the things we've learned from social research is that people tend to go online to find people they know and tend to replicate, at least in part, their social performances online. These performances, the communities that they occur in and the dialects that they represent and produce should be the critical loci for research in the postdigital age, not the technologies themselves. Texts have been recorded in spaces like Facebook and MySpace that have previously been the content of private conversation and casual face-toface interaction. We have the (mis)fortune of having a record of the social grooming of our time, which, sadly, is often misinterpreted as a degrading our social intellect. It is a manifest 
record of the facile 'Hi how are you? Fine thank you's of the older generation, which, when recorded 6 billion times might appear facile, but is, in reality, simply a confirmation of social connectedness worn smooth in repetition.

In learning particularly the postdigital signals the end to interminable debates of the benefits of 'elearning' 'eknowing' 'blended learning' and a host of other digital ways of thinking. It posits that these distinctions only cloud over the lessons that can be learned and the value that can be garnered from the ecologies in which we live and learn. Mobile learning, at the time of writing, is a victim of this kind of digitalism. Mobility in learning should refer to location independence, or widening participation. The term and the agenda has been hijacked by 'e-learning specialists' and 'digital gurus'. Mobile Learning has become a discussion of different mobile applications and application platforms and has moved away from the discussion of whom these applications need to be serving. The MUVE may offer a clear advantage in exploring gender over a dress shop in a downtown mall, but those advantages are about access and enabling rather than about any inherent value in the technology. The space being explored is a social space, not a digital one. Whatever the next digital technology may be is already at risk of the same treatment: becoming the focus of concern rather than the platform upon which change is enacted.

We hold out hope for the postdigital era. We hope that it provides the framework for an environment that is good enough, firstly, to hold an individual as they identify and develop authentic personal experiences, and secondly, to stimulate that individual to extend her/his questioning and actions in the world. In this way, as their social experiences stray into what are now called digital spaces, the digital is secondary to the relationships that form and develop, and the activity that takes place, in an environment. A central actor in the postdigital era, is, therefore, a significant, more-experienced other against whom the individual can securely test their authentic experiences. Within the postdigital era, the personal and emotional comes to the fore, and anchors cognitive development.

It is important to see the elements of what was known as 'the digital' as some of the enablers of the postdigital, in framing a person-centred, flexible pedagogy nested within a set of truly social spaces. The demand is then for capable educators, who can act as mentors in inquiry-based approaches to personal development, and thereby enable individuals to make decisions and become themselves. Postdigital aims to throw off the yoke of digital dogma, where the language of a perceived digital elite drives not only development, but also skews innovation, where innovation is only seen as being that associated with the 'latest' technology. The obsessiveness associated with digitalism seeks to see innovation as the search for meaning (or use) in the newest technology. Innovation in a postdigital era is more effectively articulated as being associated with the human condition and the aspiration toward new or enhanced connectedness with others.

\section{Reflections on the postdigital - 2015}

In June 2009 the 52group gathered from across the Higher Education sector to consider the confluence of education and the digital. The result was a position paper entitled 'Preparing for the postdigital era' (52group 2009). At the time the paper was largely met with a mixture of scepticism and confusion, a common response being 'The digital hasn't been superseded?'. Despite this, over the intervening years the term has slowly gained traction in educational contexts. 
To what extent our original paper influenced the recent proliferation of the term is of course not clear but we see the concept being employed in various locations including last year's SEDA conference 'Opportunities and challenges for academic development in a postdigital age' (Staff and Educational Development Association 2014) and a forthcoming conference hosted by Greenwich university: 'Flipping the Institution: Higher Education in the Post Digital Age' (University of Greenwich 2015). There are also numerous examples of the term casually making its way into strategic rhetoric in and around our institutions.

To mark the shift from Digital to Postdigital thinking members of the original '52group' have each revisited the term to consider its definition and relevance five years on. This is my perspective. ${ }^{5}$

\section{Post-digitalism - an evolutionary perspective (Mark Childs, 4 February 2015)}

Reviewing the Postdigital - five years on

When we were coming up with the idea of the 'postdigital' back in 2009 the phrase that seemed to sum up the concept for me was 'disappearing into use' - a phrase I heard once and have not been able to remember who to attribute it to. One quote I do know the source of is 'Technology is a word that describes something that doesn't work yet' - which is of course Douglas Adams ${ }^{6}$. There's McLuhan's idea (which is covered in Sherry Turkle's excellent Life on the Screen (1997)) that when tools become incorporated into our sense of who we are so much that they're part of our bodies they are more like prostheses than tools. Evolutionarily, technology created the species homo sapiens as much as the other way around. Then there's Stelarc who gave me a great quote for my last book: 'humans are kind of a chimera of meat, metal and code' (see Kluszczyński 2014). If that's true then technology continues to drive our evolution as a species.

Five years ago I was heavily immersed in virtual worlds. I'd just finished collecting the data for my $\mathrm{PhD}$ about learning in virtual worlds. I was part of a community of academics within Second Life (SL), all of whom I'd met there, very few I'd met in the physical world. I think I saw postdigitalism as the blurring of the lines between the physical and virtual, led largely by the development of Augmented Reality (AR) as a way to map the digital directly on to the physical. Many of us would spend our lives switching between the two, or having both simultaneously. I wasn't the only one; Gartner (those of the hype cycle) predicted that 80 percent of active Internet users (and Fortune 500 enterprises) would have an avatar in a virtual world by the end of 2011. I had the idea that the change we'd all have to go through was to learn to blend the two, which I summarised in the phrase mutatis metaxis mutandis. Unsurprisingly, the phrase didn't catch on. But neither did the technology.

We've passed that date and Google has just ended its Google Glass development; news reports are decrying it as a failure. No-one seem to have picked up on the value of AR overlaying information but have instead focused on the creepiness of surreptitious recording and how nerdy Glassholes look. Many of the people I knew through SL are now gardeners, farmers, silversmiths, vicars, or working in international development. It's not dead, but it's not exactly thriving either. On the other hand, at every social occasion everyone gets their phone out immediately anything vaguely interesting happens, takes a photo then immediately uploads it to Facebook. They then check repeatedly on what comments have appeared and

\footnotetext{
${ }^{5}$ This text was used as header to all blog / website responses reproduced in this section.

${ }^{6}$ In 'How to Stop Worrying and Learn to Love the Internet', Douglas Adams (1999) attributes the quote to the computer scientist Bran Ferren.
} 
how many people have liked it. In that way at least the online digital space pervades our lives ubiquitously. On the technology $\rightarrow$ tool $\rightarrow$ prosthesis continuum, phones are a long way along the process becoming our physical extensions.

So I would say that the idea of the postdigital, that technology just becomes incorporated into our lives so much that we don't notice it, is still an interesting process to look out for, and still has relevance as a term. It's the point at which technology really starts to work, and so is unnoticeable, is when it really starts to matter to us. There are one or two technologies we can point to and say, 'that's invisible to us', but that general transformation, to a postdigital society, or to postdigital humans, where technology truly becomes integral to us, now seems further away to me than it did five years ago.

\section{Reflections on the postdigital (Richard Hall, 6 February 2015)}

An upcoming conference on the flipped university (University of Greenwich 2015) declares that we are living in a postdigital age that is characterised by transitions of practice and redefining of the individual's relationships with technology. The conference seeks to address the question of 'What does it mean for higher education to be in engaging in a postdigital age? What does it mean for the learner of the future and of today?'

Since we met as the 52 group back in 2009 the politics of austerity continues to subsume academic and student labour. The realities of this labour are less postdigital and more focused on the interrelationships between first, lives that are subsumed under the dictates of the productive economy, and second, the use of digital technology to proletarianize work. Digital technologies are used to enforce competition and financialization, and drive the disciplinary control of data and debt, and this enforces widening inequalities inside higher education.

The process of proletarianization is global and is influenced both by national educational policy like indentured study and using Higher Education (HE) as an export strategy and internationally through the role of trade partnerships and innovations like Massive Open Online Courses (MOOCs). Thus, we witness reports of adjunct professors (Saccaro 2014) who 'don't even earn the federal minimum wage'; and we witness postgraduate researcher-led committees that 'have been pushing the[ir] University to honour the essential role that teaching assistants play in University life in the form of fair pay and treatment ${ }^{7}$; and we witness self-imposed overwork as a form of self-harm (Hall 2014a); and we witness a documenting of the processes and pains of casualisation (CASA 2015). As students and adjuncts are forced to sell themselves piecemeal they are forced to contend and compete globally. These proletarianized labourers are forced to compete as technological, entrepreneurial, and impactful. Their productive reality points to the future of the learner becoming that of a self-exploiting entrepreneur (Richmond 2014), beguiled by the promise of autonomy and ever-increasing standards of living, whilst in reality working longer and harder for lower rewards, whilst inequality widens on a global terrain. This echoes of Marx and Engel's argument in the Communist Manifesto (1976/1848) that competition and the expansion of value, driven by space-time compression across an international market, would proletarianize increasing amounts of work.

\footnotetext{
${ }^{7}$ This quote arrives from a now dysfunctional link at https://leedspostgrad4fairpay.wordpress.com/. Since Hall published this text on his blog in 2015, the authors have deleted the website.
} 
Across globalised HE, we witness zero-hours contracts, outsourcing, the need for collective action like the 3 Cosas Campaign (2019) and so on. In a competitive, transnational educational market, academic labour rights will be threatened by the equalising pressures of transnational competition and productivity, which includes new forms of competition from private providers. These might be rival organisations with degree-awarding powers, partnerships of accrediting organisations operating through MOOCs, or hedge funds providing venture capital for technologically-driven innovations. Here Will Davies' recent work on neoliberalism (Davies 2014) is useful enables us to analyse capitalist work inside the flipped University, in light of self-exploiting entrepreneurial activity that is:

- enacted through new combinations of technologies and practices to inject novelty into the circuits of capitalism;

- operating through counter-acting norms that can never be stabilised;

- rooted in a new productive environment that accommodates power: first in expanding the time-scale for returns; second in expanding the arena for competition; and

- grounded in vision and desire.

The future of the learner is to be recalibrated as an entrepreneurial life, in order to widen the orbit of productive labour. In part, this is done through the individuated, technologized Self. It is also achieved through the entrepreneurial recalibration of the collective labourer. Critically, this means that universities as businesses are restructured for the production of surplus value, through organisational development, knowledge transfer, impact, technological innovation and so on. As the IT Consultancy Gartner notes:

Digitization is reducing labor content of services and products in an unprecedented way, thus fundamentally changing the way remuneration is allocated across labor and capital... Mature economies will suffer most as they don't have the population growth to increase autonomous demand nor powerful enough labor unions or political parties to (re-)allocate gains in what continues to be a global economy. (Gartner 2013)

Those working in the University need to recover themselves from narratives of organising principles and curricula that are allegedly postdigital and flipped, in order to address the following questions:

1. How might the notion of political decision-making or action be harnessed in ways that broaden the horizon of political possibility inside-and-beyond the University?

2. How is it possible for individual agency and collective institutions to be criticized and re-imagined simultaneously, in order to overcome neoliberal narratives of technologized, self-exploiting entrepreneurial activity?

One possibility lies in the idea of the Commons and the praxis that emerges from commoning as a global idea of socialised solidarity, rooted in mass intellectuality and open co-operativism (Hall 2014b). This is a mechanism for framing a socially-useful higher education that recognises its own alienation. Refusing the postdigital, flipped proletarianization of the University hinges on the creation of a 'direct form of communal manifestations of life carried out in association with others - [that] are therefore an expression and confirmation of that social life' (Marx 1844). This might be realised in spaces that 
incorporate increasingly alienated social forces in the global North, as well as those largely ignored in the global South. It demands a more mature discussion of the possibilities for pedagogic production as a social activity that are for-society rather than for-profit.

\section{Postdigital revisited (David White, 6 February 2015)}

I was in a vexed mood when I wrote my 'Escaping the kingdom of the new' (White 2014) post reflecting on our postdigital working paper back in 2009. The edtech community were still in a 'Web 2.0' fuelled miasma, heralding each digital platform as the next-big-thing. It was a slavish attachment to the 'new' that was blind to the simple duplication of existing practice from the analogue to the digital.

Nearly 5 years on the term postdigital is becoming accepted in higher education circles as describing the normalisation of the digital in almost all aspects of activity. Elearning is a good example of this and huge success in some senses. I could prove this, for example, by pulling the plug on any university's Virtual Learning Environment (VLE) and watching a riot break out. These kinds of tech, those that predominantly use the Web as a means of shuffling content are quickly 'disappearing into use'. They have become postdigital precisely because they don't challenge the underlying way we run our institutions or engage students.

Meanwhile many students themselves struggle to answer the question 'how do you do the research you need for your assignments' because for most it's difficult to imagine the answer could be anything other than 'Google'. Similarity the incorporation of the smartphone into the fabric of how students study is already postdigital to the extent that it's been described as 'mundane technology'.

And yet moves to shift pedagogy to more collaborative, peer supported or open models are still met with confusion and trepidation. We have managed to 'disappear' much of the technology but predominantly in the service of mediocre models, efficiency and scale (MOOC?). One simple reading of this is that practice evolves at a much slower pace than technology. Another would be that institutions incorporate the 'new' only to serve what they already understand.

We appear to have moved from evangelising the new and shiny to using it without question. Perhaps it's time to re-examine that of the digital which has become 'post', to question the embedded and ask if it is pushing boundaries or simply ossifying business-asusual, petrifying forms of practice we assumed the 'new' of digital would disrupt.

More fundamentally the move to the postdigital is submerging ideology: big-data, search engine optimisation, learner analytics, we-recommend-this-course-based-on-yourprevious-attainment-levels etc. The surface this presents is one of apparent neutrality and in our cultural naivety we don't recognise, or are barred from seeing, that the underlying algorithm has been marinated in a bath of vested interests. The new normalcy of being connected has created a postdigital environment in which ideology can be embodied in code a form that most believe to be free of bias.

I believe that in the same way Media Literacy shines a light on the political, cultural and ideological assumptions shot through broadcast media, Digital Literacy should make visible the the very same which is crystallised in code. It might be too late though, we may already be completely postdigital. The code we need to 'see' being too many layers down from the shiny surface of the technology we barely think about anymore.

\section{Looking back at 'postdigital' 6 years later (Dave Cormier, 6 February 2015)}


Two weeks ago I tried to convince Oscar (my eight year old son) that he wanted to learn to code. I explained to him that it would allow him to do really cool things, like design his own stuff on a website, or create a database for his coin collection. I didn't get a ton of feedback from that discussion, I think the floor immediately TURNED TO LAVA. I'm not sure why that happens in my house on a pretty much daily basis. Anyway... a week or so later, in the midst of me trying to get some shovelling done, Oscar looks at me and says 'I'm really looking forward to learning to code with you'. Cool right? I thought it was at first...

What I thought I was selling to my son was the ability to do crazy things on the Internet. Of course... he's had a blog since he was four. We've done vines, instructional videos, and, a while ago, podcasts. He's a performer my son... and he not only wants to post things, he wants to know that people have seen them. He wants to say 'cool huh?' to everyone who's seen what he's posted. Coding was a con job to try and get me to stop shovelling snow out of the driveway and come play with him. This the brother of Posey (six) who has only just come to terms with the fact that the LED screen on the telephone does not contain a moving picture of her GrandMaman.

14 years ago, Prensky (2001) suggested that we may have a generation of digital natives. That these kids had a relationship to technology, a facility for it, that we digital immigrants couldn't understand. He may have been right, I think, in a particular way. (EDIT for@donnalanclos: not the 'facility' part.) When I look at my children and I see them look at what I think of as a 'digital technology' they don't make a distinction. They don't care if they are talking to GrandPapa on Skype or on the phone... they are talking to GrandPapa. My kids don't care if they are performing on the stage or on video, they are performing. Sure... they are different, but they aren't different for 'digital' reasons, they are different for human reasons. They can type to Grandpapa over Skype (actually, mostly by sending inappropriate emoticons) which they can't do on the phone so the phone isn't as funny. They feel the audience more directly when they are acting on the Confederation Centre stage, but not for as long as they do when they post a video.

Postdigital. That's what my kids are. It's a funny expression borrowed from the art world that six of us tried to use to describe how we saw the need to say 'digital' disappearing. It mirrors its philosophical mentor 'postmodern' in the sense that to be 'post' digital is also to deny that the digital should have ever been a foundation that we built on. The digital technologies that were once so complicated to use on the Internet have become mostly transparent (though not, importantly, socio-economically transparent). There was an interim space where saying digital might have been necessary... as the weight of effort to do the simplest connecting online was huge. The computer, for better and for worse, if fading into invisibility next to the board marker and the TV screen.

The ability to connect to more people faster certainly changes things, but the change has already happened.

\section{Reviewing the postdigital (Lawrie Phipps, 6 February 2015)}

At the time of writing the original thought piece, 'Preparing for the postdigital era' (52group 2009), we were looking to articulate how technology is not a driver of social change, but an enabler. Postdigital has taken many paths since 2009, referring to subsuming of technology into society so that its presence, and to some extent the continued proliferation and innovation, becomes a social and cultural norm. However, it should be noted that this perspective is only from a global north perspective. 
My focus on the postdigital looked at how some individuals have been enabled to change or modify academic practices. Most of the observations in this area have come from the social media interactions, for example individuals having access to a ready means of publishing through blogs and other social tools. At the moment there is a distinctive, and growing, group of academics and academic related staff that can be identified and recognised through the online promotion and increased visibility of their work. The way that these individuals interact and collaborate with others through media such as Twitter, Facebook and blogs, and importantly how they draw links between the different media, is also a defining characteristic.

Peruse any conference information or mailing lists and you will identify that digital is currently in vogue, and it has mostly replaced the prefix 'e-'. For the group of academics referred to previously, the tech-focused distinction has disappeared. To them digital is already invisible, new media are conceived in terms of affordance. They see these tools as an artist would see the brush and canvas, they are there to be used to create and articulate an image held by the user. It is the exploiting of these affordances that make them distinctive. Social media as littered as it is with academic shrapnel showing how people are thinking and developing their ideas is fertile ground for postdigital behaviours. As ideas and information proliferate, so networks and ad hoc communities emerge, often individuals collaborating and never meeting. Most of this happens in the open, reaching new audiences, but more importantly it is almost an open invitation to participate.

In the past individuals may have strongly identified with organisations, institutions or research groups. The postdigital behaviours have begun to alter these relationships which are now more fluid and agile. Relationships develop and fade as needed.

What I didn't understand about postdigital behaviours at the time of the original paper was that they do not only relate to idea of affordances of technology. The nature of change, especially in education, has gone through a shift of emphasis. The idea of a change process occurring with fixed start and end points is less of an issue. Perpetual beta, the way in which some software is always supplying features or fixes to ensure ever greater usability, can now be seen in the way in which we work and live, for example multiple career paths. If postdigital has a set of characteristics, then the way some organisations seek to create space and time to enable and encourage their staff to always look for ways to innovate would be part of that set.

Understanding how change is happening, and the speed with which students adopt new behaviours and technologies, will have huge implications for staff development. Whilst not mutually exclusive, is it better to have an accredited lecturer who has done no professional or personal development for two or three years, or a lecturer without accreditation, who seeks to constantly enhance practice and understand the changing nature of students? The impact of the journey that brought us to postdigital reveals that to prosper at work and socially, individuals need to behave with more agility and flexibility, and of course with the ability both to recognise that innovation is permanent and to accept continual change.

\section{Reflections on the postdigital - 2019}

The impact of conformity in education (Dave Cormier, 27 February 2019)

In 2009 I was fortunate enough to be part of a conversation that led to 'Preparing for the postdigital era' (52group 2009). This week we all got asked to do an eleven years later reflection, and, as I'm at an National Science FOundation funded retreat (at Biosphere 2!) 
talking about equity in STEM education, I thought it made sense to try and use the postdigital as a tool to interrogate equity and education.

Let's start here. Social media isn't a jerk.

I wish I could send a smack-upside-the-head to eleven-years-ago-dave. When things like Twitter were still places of positive connection and occasional porn sites jumping your hashtag, we had this idea that the connection between people was somehow going to be different. We told everyone to join Twitter if they wanted to be smarter, better, taller! elevenyears-ago-dave didn't understand that it was inevitable that the rest of the human experience was going to impact those spaces. Twitter was full of people in 2009 and full of more people now in 2019.

Here's the thing... it's not like we didn't know the world was full of jerks. If you'd asked 2009-dave if there were jerks everywhere, he would have nodded sagely. This is why I can't believe that he didn't see 2014-twitter as an inevitable outcome. In 2014 the jerks found Twitter. Or, at least, they found out how to use Twitter in a way that allowed them to show they were jerks. They yelled at people. They abused people. People were harmed. It is still happening. They have made the Internet very unsafe for many people. They were mean to people because they were different. They attacked people who weren't totally dedicated to the privilege of the jerks. People seem to do that from a desire for power and attention. They also do it to find a sense of belonging with others who share a desire for power and attention. That desire didn't materialize in 2014.

In my work I always say that technology reinforces pedagogy. The technology here amplifies the jerk... it doesn't make the jerk. More importantly, the technology ISN'T the jerk. And when we see 'social media' as a thing, in and of itself, rather than a just a way people platform themselves - no different than the speaker platform at Hyde Park - we miss the solutions. Our technologies are good ways to find a jerk, but the solution to that is to deal with the jerk, not the technology.

So. social media is not a thing that needs to be fixed. People connecting with people is a thing. Jerks are a thing. Jerks are not a digital problem. Jerks are a real-world problem that has been around for a long time. We need to get past the digital and fix our real-world jerk problem. And, as we go along, we have to think about how our systems help create those jerks.

\section{Part two - we actually can negotiate a new social contract}

A thousand years ago, steel encased thugs with sharpened crowbars (swords) were wandering around the countryside in Europe punching cows. I'm not joking. They were jerks. They were literally punching cows, as well as stealing people's stuff and, all too often, killing random, innocent people. The church, not usually the benevolent actor in medieval history tales, had an idea. They created the Peace and Truce of God movement. Local clergy would make a pile of all the saints relics they could find and try and get knights together to swear to this new social contract. Saints relics were the brand that enforced that change. The peace of god was an attempt to try and protect people (clergy were particularly singled out as people who needed protection) but it extended to property and livestock. The truce of god was an attempt to have days that violence was off limits. Sundays. Holidays.

Technology (horse + sword + armour + castle) had created a societal problem that needed to be addressed. A thousand years later you can see the impact of the Peace and Truth of God in our culture. They actually looked at something that was a side effect of a technology and went out and renegotiated a social contract to get it done. It actually worked. 
It took 2 or 3 hundred years... but it you look at what words like polite, or proper actually came to mean in that society, lots of it can be traced back to that original (admittedly selfinterested) work by the church.

The church is no longer the societal institution threatened by free-roving jerks who've slipped the bonds of the old social contract. Democracy is, to what extent we have it.

And we need a pro-social web dammit. And we need to make it.

I honestly think that our education system can be that brand that allows us to make this change. Our education system, however, is often kind of a jerk. That education system is a systemic structure that teaches us to believe in power over people.

Deciding what knowledge someone needs is an exercise is having power over someone. Assessment, particularly, is grounded in power structures. Learning as its been traditionally perceived by our culture is a sorting process. Whether it is the way in which we separate the 'expert' and the novice through degree granting methods or the bell curve which either secretly of overtly lives under our \% system, it is the way by which we apply different class markers to people. It is a 'we-making' process and it is, like all we-making processes, a 'them-making' process. We are literate. We have a PhD. We are the teacher. We are an A student. All of these things exclude the people who are not part of the 'we' belonging.

Those expectation are... not equitable. They privilege a certain background. They privilege a certain kind of thinking... or knowing. In a sense, our education system is a training ground for the privileges of conformity. A conformity that is certainly easier for many, and a conformity that is totally inaccessible to many. It teaches people that conformity to power is what belonging looks like.

So let's go back to our social media jerk. Jerks go online to exercise their power by attacking people for not conforming to their sense of belonging. The louder they yell... the more they run in a pack... the more they attract people to their conformity group and the more firmly they exclude the them that don't conform. This is the system of power that our schools represent.

I'm not saying that our schools necessarily make jerks... what I'm saying is that the ways on which knowing is negotiated in our schools supports this way of negotiating truth. If you have power, you can be right. If you have power, you can decide who's right. Also... there are things that are RIGHT and learning things about the world is about trying to find the right answer.

We need our schools to replicate models of inclusivity and equity that are not about the imposition of conformity. That means that we accept people the way they come in the door, and we help them come up with answers that belong to them.

Do different technologies have different affordances that allow jerks to be more jerklike? Sure. But that postdigital lens asks us to look beyond the 'Twitter is a cesspool' argument. When we identify the technology and not the people beyond we missed the systemic cultural practices that are helping to shape the people who are the bad actors on those platforms.

\section{Education, technology and the end of the end of history (Richard Hall, 3 April 2019)}

After the fact, and following a decade of attempting to reconsider my position in light of intersectional and indigenous struggles, I note that the 52group consisted of white men of a certain generation, with plenty of social and intellectual capital, each working in the global North. It would be interesting to critique these positions and possibilities, in light of status, 
privilege and power. That is not to say that the original members of the group did not do this, just that there is more to say.

\section{ONE. No shade in Capital's shadow.}

When the 52group originally met to discuss the intersection of education and digital technology the world was very different. It was more hopeful for connectedness and meaningful forms of connectivity. Such forms of connectivity were rooted in the humane, and in liberal values, which naturally emerged from the dominant political economic order. This order tends to describe the relationship between technology and society (or technology and the reproduction of that society) in positivist or determinist terms. Moreover, it does not help us to reimagine society in the face of crises, precisely because technological determinism reinforces the idea that we have reached the end of history. As a result, the limits of our imagination can only be shaped by finessing our future through our capitalist present.

Yet, in the intervening decade we have witnessed: the ongoing struggle of the global economy to overcome the crash of 2007; the rise of economic populism and the reinforcement of political binaries; the imposition of austerity politics, with differential impacts for specific populations; an inability to deal with crises of the environment; and on and on. We have witnessed the ongoing separation of politics and economy, such that solutions to these ongoing ruptures cannot be imagined beyond the existing, dominant mode of production.

This dominant mode of production warps our imagination through imposition of technological solutions. Such solutions are used not for humane values, rather for the generation of surplus that can be accumulated. Surplus emerges in the form of economic value, wealth in the form of profit or money, or time that can be diverted to more work, either collectively or on the individual self. Technological solutions are central to the accumulation of surplus, and as a result they are used inside capitalist production processes to discipline labour, to drive efficiencies in the use of labour power, to create new commodities, and to generate new markets.

\section{TWO. Techno-discipline.}

At the intersection of education and technology, the work of students, academics and professional services staff is disciplined through workplace and attendance monitoring, performance dashboards, and the imposition of rating and excellence systems that seek to reshape affective labour processes. The labour processes of students and academics are increasingly commodified, as pedagogic processes and content are opened out such that new infrastructure and data services can be extracted by private providers and resold into the sector. The teaching, scholarly and research activity of the University is conditioned by discourses of employability, entrepreneurship, excellence and impact, and shaped by the intersection of performance data around debt, future earnings and learning outcomes. Moreover, these intersections are enabled globally, through flows of resources from the global south to the global north, with commodity-dumping in the opposite direction.

Individual bodies are conditioned collectively against dominant norms of production, shaped by an idealised view of how education and technology are generative of productive, human capital. As a result, digital technology is folded inside an apparently never-ending terrain of competition at the level of the individual, the subject, the institution and the nation. Digitally-reinforced performance metrics impose digitally-reinforced performance management. 
Moreover, in this idealised view of production, in the technology-rich university of the global north, the reproduction of enriched human capital rest upon the ongoing exploitation of other bodies. These bodies undertake estates-related activities, cleaning, porterage, cooking and purchasing/logistics, at work and in the home. These bodies exist in low-wage, subeconomies that are often precarious and lacking in labour rights, such as pensions, maternity/paternity cover, holiday and sick pay. These bodies are often marginalised along intersections of gender and race.

\section{THREE. Ongoing techno-colonisation, exploitation and expropriation.}

The only space for radical imagination appears to be in the further, ongoing colonisation of the body and the Self by digital technology, as a means of generating surpluses. This is not the 52 group's original conception of 'the act of [technology's] colonisation, or appropriation, by people into their lives.' (52group 2009) Rather it is Capital's colonisation of the soul in the ongoing search for surplus. Here, there is an overlay of these terrains of competition in ongoing corporate processes of exploitation and expropriation. Such processes limit the energy and capacity that societies have for re-imagination, precisely because these become bounded by the competition between humans and machines. Again, the 52group argued that 'As digital technology is culturally normalised it becomes ever more transparent' (52group 2009), yet whilst technology and its commodities may be built upon ideas of openness these ideas do not enable transparency. Rather they are a legal terrain for the enforcement of privatisation and commodification through intellectual property, copyright, and patents.

Human engagement with technology has always had a contested history, in which individuals or groups or States attempt to break or harness specific technologies for particular political ends. Now, such contestation is amplified at the boundary between the human and the development of 5G cellular networks, cloud native applications, artificial intelligence, nanotechnologies, convergent technologies including biotechnologies, and the Internet of things. Interactions at these boundaries then enforces human-machine intersections with digital, monopoly capitalism in the form of Google, Microsoft, Amazon, Facebook and Apple, and the rise of alternate geopolitical rivals, in particular from China. As a result, technocolonisation of what it means to be human is amplified.

In the original, 2009 conception of the postdigital, the 52group wrote: 'Not only is the digital subservient to the social, it is, in some ways (and soon most ways), transparent.' (52group 2009) Over the course of a decade this statement has become a dystopian pivot for understanding more than the relationship between digital technology and the social. It becomes a pivot for understanding the convergence of the personal/the person and a range of technologies (cognitive, biological, nano), in order to subsume what it means to be human fully under the dictates of capitalist reproduction. This has been described in terms of the post-information human or the post-human, or analysed in terms of what it means to be posthuman. In these descriptions, society has viewed technology through an economistic lens, reinforcing the separation of politics and economics, and denying the potential for a reintegrated political economy that radically reimagines society. As a result, social reproduction cannot be viewed beyond the lens of capital, and technology cannot be viewed beyond the lens of expanding the field of accumulation.

FOUR. Techno-humanism at the end of the end of history.

In a crucial part of the original statement, the 52group write: 
The obsessiveness associated with digitalism seeks to see innovation as the search for meaning (or use) in the newest technology. Innovation in a postdigital era is more effectively articulated as being associated with the human condition and the aspiration toward new or enhanced connectedness with others. (52group 2009)

Existence at the alleged end of history can only define enhanced connectedness through the dystopian subsumption of the flesh under emergent technologies like biometrics, neurotechnology, human genetic engineering and 3D bioprinting, and speculative technologies like the exocortex. The terrain of aspiration is shaped through the exploitation of the flesh and of the mind, through the augmentation enabled by technology, and the ongoing expropriation of what it means to be human. Of course, it is imperative that we recognise that these moments of exploitation and expropriation are rooted in wider, intersectional injustices.

Populations struggle to imagine futures beyond socio-economic or socioenvironmental problems where these do not emerge from experts, technocrats or technologists. Human-machine or environment-machine augmentation are sold as enhancement; as logical, next transhistorical steps. This is precisely because our imagination cannot be allowed to view solutions to such problems as anything other than mechanistic and economy-driven. They are devoid of political content, in part because imagining a different history is too threatening to the established order.

Yet, this is exactly what is required - a radical, political horizon, which is reinforced through a radical, political imagination. A radical, political imagination that seeks to renegotiate the relationship between humans and technologies, grounded in the interdisciplinary reintegration of life. So that it becomes possible to reimagine the relationship between humans and technologies at the end of the end of history. So that it becomes possible to reimagine the relationship between philosophy and the natural sciences, or between the social and natural sciences. This is a reintegration of the material modes of production with what it means to be human.

In terms of the intersection between education and technology, the focus must shift towards intellectual work, as opposed to academic labour, being recombined at the level of society to ensure that knowledge is socialised rather than privatised. Moreover, productive technologies need to be collectively controlled, such that the things that societies actually need in order to flourish, namely socially-necessary goods and services, can be produced in ways that reduce the waste of time, energy and lives. Waste, the counterpoint to surplus, emerges from the production of useless commodities.

The integration of technologies with a new political economy reduces the space and time required for the production of the things needed for self-sufficiency. It widens as base for autonomous existence. The very automation or human-machine augmentation and symbiosis that capital demands and develops in order to discipline and control labour makes possible an exodus from the society of capitalist work. This potential erupts through the radical redisposal of the surplus time that arises as an outcome of that automation, alongside the new ways in which different groups can interconnect in that surplus time. At issue is less the reality of automation at the end of history, and more the role of human dignity in rupturing the end of history.

This rupturing is the end of the end of history. The liberation of science and technology from capital's competitive dynamics emerges as a new political horizon erupts. This is central to moving beyond capital's digital colonisation of humans, such that it can exploit and expropriate what it means to be human and humane. Instead of the intersection of 
education and technology, we might speak of convergence, such that students, professional services staff and academics are able to focus upon the relationship between freedom and necessity, in order to widen the former and reduce the latter.

At the end of the end of history, can we make it possible to focus on alternative educational practices that develop socialised knowledge as a direct, social force of production? At the end of the end of history, can we reimagine ways to deny capital's abstract, normalised monopoly over the productive resources and potential of society? In this moment, it may be that educational contexts form dynamic sites in the struggle to recuperate social productive power, where they are predicated upon the dignity of inclusive and participatory work. A starting point is recognising flows of power and privilege that are reinforced digitally, and opening out political structures for refusing techno-fuelled colonisation. ${ }^{8}$

\section{The Shiny Show: Why the postdigital is dull. (Ian Truelove, 5 April 2019)}

In 2009 I helped to spend the last of my first proper research funding by attending an event at a posh royal estate somewhere down south. A group of excited and slightly mischievous edtech chums embraced this surreal situation and used it to open up our thinking to something new. Although I subsequently discovered that Nicholas Negroponte coined it first in 1998, we thought we'd invented the idea of the 'postdigital'. But Negroponte's timing was out: unearthing of the notion of the postdigital made so much sense to us all at that particular point in time. We'd just delivered a really interesting project looking the educational potential of a multi-user virtual world called Second Life, but as an artist, I was only every really interested in the creative potential in such new media forms. I still am. Although I can recall seeing the absolute sense emerging in the 52group discussions as this postdigital definition was crafted, I distinctly remember getting very grumpy about the lack of creative potential in it. For me, the bleeding-edge of a new digital technology is where a space opens up to make new art, but the core idea of the postdigital is that it describes a time when that bleeding-edge has passed through the cutting-edge phase, onto the 'oh look everyone, it's new', and arriving at its 'I don't really notice it anymore' postdigital conclusion. The postdigital is when the shininess of the digital goes dull.

During the Open Habitat project my avatar, Cubist Scarborough, sent my first tweet from inside Second Life. It read, '03/03/2007 23:23 Perfecting my Second Life holograms at my land in the Rossa sim'. I didn't really know what Twitter was supposed to be for but my co-collaborator, Graham Hibbert, was testing out a Second Life to Twitter gadget that he'd coded, and I was helping him out. When I started using Twitter properly as my 'real' self, I used it as a creative medium. Nobody really knew what Twitter was supposed to be for, so I took advantage of that openness and mucked about. At one point I decided that Twitter could be a craft medium rather than a communications platform and posted a series of knitting patterns consisting of repeated characters. I enjoyed challenging my followers when Twitter was an emerging medium, but when Twitter became firmly established and there was a 'proper' way to do it, I gave it up. Twitter became postdigital, and so I lost interest.

Once the digital shine wears off, I look for something new. In recent years I've been making artworks using the new generation of virtual reality headsets, but even that is losing

\footnotetext{
${ }^{8}$ Richard Hall supplemented this contribution with a wide bibliography which can be found at http://www.richard-hall.org/2019/04/03/education-technology-and-the-end-of-the-end-ofhistory (Hall 2019).
} 
its sparkle. Long before a technology starts heading towards the postdigital it is time for me to give it up: the postdigital is an alarm bell that tells me it's time to move on. So, what's the next shiny new technology packed full of creative potential? I think it's probably augmented reality (AR). Not that rubbish 'magic window' thing on your phone, but the full stereoscopic headset-based projection of the digital onto the physical via devices such as Microsoft's Hololens. Just let me get my hands on one of those beauties and I will make interesting art with it. This technology is so clunky and expensive at the moment that I reckon I have a good few years of bleeding-edge playtime before everyone gets a pair of AR glasses, and we laugh about the tiny screens that we peered at on our phones in the 2020s. When AR becomes postdigital, I'll be ready to retire. Maybe I'll swap my iSpecs for reading glasses and read an analogue book.

\section{Too postdigital (David White, 12 April 2019)}

Back in 2009 I was one of a group of men with the time and money to get together and attempt to make sense of what was going on with digital technology and the Web. What we came up with was the notion of the postdigital in our original proposition 'Preparing for the postdigital era' (52group 2009). It's a short document which explains a simple idea: now that digital tech and the network are so prevalent our thinking should go beyond the tech in-ofitself and focus on the way our interactions are played out in/on the digital.

For me the idea was a useful counter to techno-centred narratives of the time which pushed new platforms such as Facebook and Twitter as things everyone should 'get into' but without really discussing why. It all felt highly uncritical and implied that the tech, rather than those using the tech, was ushering in a new era. I was bored of talking about how 'revolutionary' technology was and saw the postdigital concept as a good way to take a shortcut past the shiny surface of the machine to discuss what might be happening in sociocultural terms.

At the time the idea was met with a mixture of mild confusion and ambivalence. Broadly it was misunderstood as an attempt to negate the importance or existence of the digital and just an exercise in coining a phrase. It appeared we had decided that just at the moment digital went mainstream we thought it would be radical to not-talk-about digital. There is some truth in this but things have moved on...

\section{Postdigital in 2019}

There is much discussion of how the technology is becoming 'transparent' in the 2009 paper. This transparency is framed as an opportunity to be less tech, and more person-centric when considering digital. In 2019 we are unknowingly postdigital, not because our tech objects have become transparent but because the network they are part of is not, and never has been, visible. We don't 'see' the infrastructure because we are still enthralled by the obscuring newshiny surfaces of our phones/laptops/tablets/tvs. We are happy to swap understanding for 'intuitive', 'frictionless' and convenient tech. This is reasonable but dangerous.

I don't want to return to the days when the tech infrastructure was so tenuous that I spent more time trying to get-it-to-work than doing the work I needed it for. Nevertheless, I think those moments of failure, when the connection goes down or the software crashes, are important in revealing just how quickly we pass through the digital to the postdigital. In 2019 many people are surprised when the tech stops working, whereas I'm constantly surprised it works at all, given how complex it is. 
What we have failed to comprehend in the last decade (or didn't want to think about) was the complexity, power and intention(s) of the network and those that control it. The network has never even gone through a 'digital' stage (in the terms of the paper) where we get over excited about its newness, it has in some sense never existed in the public consciousness even though it saturates our lives and our spaces. When we buy a new phone we are told about how amazing the camera on it is, not the fact that we are renting a node on a network which is a vast, relatively unregulated, corporate space.

Only very recently has the nature of the network appeared via stories of 'bad actors', the manipulation of democracy through globalised targeted propaganda and the aggressive use of 'personal' data to feed uncanny algorithms. In 2019 I'd suggest we need to be less postdigital about the network. There is ongoing work to reveal the network, making it untransparent and to educate and regulate towards a place which supports citizens over and above the drive for power and capital. The trouble is that it's super boring compared to the latest app or a few more megapixels and if you want keep a secret, don't hide it, just make it super-dull.

While we play at being human on the surface of the network we simultaneously being dehumanized, converted into forms of interoperable data. Here is where Donna Haraway's 'A Cyborg Manifesto' was so prescient. Writing before the Web in 1984 she highlights our rush to convert all things into the universal 'exchange' language of code:

No objects, spaces, or bodies are sacred in themselves; any component can be interfaced with any other if the proper standard, the proper code, can be constructed for processing signals in a common language. Exchange in this world transcends the universal translation effected by capitalist markets that Marx analysed so well. (Haraway 1984/1991: 163)

There is a section in the original postdigital paper which speaks of our hope that the digital environment will be a place where we can 'become' in positive and connected ways. It's difficult to retain that hope in 2019 but we know that negative stories travel the fastest. Ultimately society has moved online, and while it might seem misanthropic, I'd argue that the pettiness, hate and abuse of power is evidence that we are now postdigital and that this is what it looks like when (almost) everyone gets online. More sinister is that while this sound and fury is played out on the cultural meniscus of the Web we are simultaneously being codified in the networked waters that lurk beneath. Ironically it is this process of digitising and 'codifying' being which is moving us from the digital to the postdigital at such a rate we can't even see it happening.

\section{Some thoughts on the production of the original position paper}

Looking back over the original position paper I feel a mild sense of guilt. We appear to have been naively working on the assumption that the technology was neutral. In 2009 none of us were really aware of how our data was being used and abused. If I recall correctly the principle that 'if the platform is free to use then you are the product' might have been starting to surface but most of us interpreted this as the risk that we might have to look at a few adverts.

Certainly my thinking in this area was still based on broadcast media and crudely targeted ad campaigns which had to scatter their messages far and wide in the hope of making a sale. We hadn't understood the manner in which politics and ideology could be embedded in 
code. We were keen to develop language and models that would somehow explain what was really going on if you could pull away from all the 'newness' and increasing corporatisation of the Web which up until then had mainly been endearingly shoddy, slow and full of nerdy guys like us. We wanted to mansplain what was actually interesting to all these newcomers who we felt were hypnotised by the shiny tech. We wanted to own what it all meant, in the same way we had owned what it all was.

I still believe postdigital is a useful concept because it shifts emphasis away from the technocentric. I also feel uneasy about our motivations for developing the idea and the manner in which it came about. It's fair to say that the reason we didn't discuss the potential negative aspects of the digital is because we were not in marginal or precarious positions and so didn't have perspectives that arise from vulnerability. (perhaps I should say 'I' not 'we' as I can't speak for the other members of the group).

\section{There's three ways that the postdigital can grow (Mark Childs, 14 April 2019)}

\section{The future is ours so let's plan it}

I've recently completed authoring a course for the Open University on the future of educational technology. The assignment the students have been set is to develop an outline for a course in which they make their own prediction on a particular theme.

To give the students some framework I provided a few examples of good predictions, and lots of examples of bad ones (there are far more bad than good). I also wanted to abstract the process a bit and look at what made them good, and what bad. Although there are lots of futurologists predicting the future, there are very few conceptualising how you make a good prediction.

One I drew on is an author called Edward Cornish. In his Futuring: the Exploration of the Future (Cornish 2004), he refers to 'Miracles that Were Postponed'; technologies that were feasible for a long time before they were adopted. An example is that of the videophone. Although video calls were technically feasible in 1929, and 'spaceographs' featured in serials such as Flash Gordon throughout the 1930s, they only became a daily occurrence in the last decade. The expense and inconvenience of specialist equipment to conduct the calls limited their use, the lack of use limited their demand, and the lack of demand limited further investment. It was only when the technology became cheap enough to have a camera placed in every laptop that the barrier to use was overcome. The lesson is that just because something can be invented, that doesn't mean it will be used enough to cross the threshold of becoming transparent. Of disappearing into use. Of becoming postdigital.

It's only now, 110 years since E. M. Forster predicted a world connected by videoconferencing (Forster 1909) that videoconferencing is almost there. My mum is 86 and she does it all the time. It's usually a click or two away from working, but sometimes there will be someone whose microphone isn't on; or someone who drops out when you add a third person. But the technology is almost transparent. One day soon, someone in the world will start a videoconference with some sentence other than 'Can you hear me?'

The three ways that anything can grow are, of course, good, bad and mediocre. For the six of us in the 52group to identify these in advance, eleven years ago, was a task we were inevitably going to fail at to some extent. Eleven years on though, I thought I'd look back at how well we did.

That's good 
The 'good' in this context are those technologies that actually have become postdigital. The prime example of a technology that has disappeared into use is the smartphone. Anything you can do with a smartphone is now invisible as a technology. It's postdigital in the sense we meant it back in 2009. Taking a photo and uploading it to Instagram. Finding out how long it takes to get to from Milton Keynes to Hunstanton. Googling whether or not it was Tavener who composed The Protecting Veil (it was). Reading 20000 Leagues Under the Sea. These are all events I did yesterday that fitted seamlessly into my life because they are only a splitsecond away. At no point did I think 'I need to use some technology to do this'.

The smartphone as prosthesis is something I talked about in 2015, and in later pieces I've drawn closer comparisons between smartphones and the Acheulean hand-axe, a mobile device carried round by an early hominid called homo ergaster (about one and half million years ago). I bought one a few years back and incredibly two of its dimensions are exactly the same as the phone I had then: $140 \mathrm{~mm}$ long by $72 \mathrm{~mm}$ wide. It has multiple applications, you just have to rotate it and grip it at a different angle to switch it from flaying, to scraping, to digging, to cutting. Back then it extended the ability of homo ergaster interact with their world. The phone does the same thing for us today. It's not just a part of our practice; it's part of us, and so we hardly notice it.

\section{Bad}

The 'bad' in this sense isn't necessarily a bad technology, it's just bad at becoming part of the set of postdigital technologies. Artificial Reality and Virtual Reality still aren't technologies that are easy and immediate. Virtual worlds (except as an extension of computer games, for example Fornite Creative) are actually used less than they were ten years ago (Schultz 2018).

We can all point to technologies that have been predicted as changing the nature of education and still haven't been adopted, not because the technology didn't work, but because the rationale for adopting it never became manifest, or because it was just a bit too difficult, or expensive, or unreliable, to be adopted. Even technology that takes up too much space in the classroom will struggle to find a place, literally. How many of us have interactive whiteboards hidden away in a store cupboard? If your average technology conference was limited to presenting the technologies that teachers are actually likely to be using five years on, it would probably take place in a garage rather than a hangar.

Elsewhere we've seen other forms of resistance to the growth of the digital, that's not just because the new technology isn't usable, but because people really like the one they've already got. Physical book sales continue to rise (Howe 2017), particularly amongst young adults, because of the tactile nature of a physical book as well as the greater sense of tangible ownership that is part of possessing actual objects. The growth in vinyl is the same, though smaller than the drop in CD sales (Porter 2019).

The degree to which the physical continues to be set apart from the virtual, despite all predictions to the contrary, is because many people still cling to the notion that somehow interacting face-to-face has an intrinsic value that isn't met by online interactions. In Errant Bodies, Anne Pasek (2015) critiques the attempt to 'problematize the erasure of corporeal identity in virtual technologies' by those who describe the 'impoverishment of person-toperson intimacy' that occurs when communicating via technology as a form of 'cultural autism'. Pasek's criticism of authors such as Clare Balsamo in her Technologies of the Gendered Body (1995) or Sherry Turkle in Alone Together (2012) is that theirs is a very neurotypical view of what constitutes ideal human interactions and, for many, the more limited type of connections afforded by technology is preferable. Pasek points out that this 
presumption that the noisiness and connectedness of shared corporeal space is natural to everyone, and therefore is always better is, in actuality, not a given. However, the rhetoric we see when people criticise online social interactions continues.

\section{And mediocre}

This is the point at which my extended Rocky Horror reference falls down. By 'mediocre' I mean the technologies that have only partially made the transfer from technologies that don't work to technologies that work so well we don't notice them. They might only be 'mediocre' in the degree to which they've become postdigital, but really these are the technologies I wish I'd been focusing on for the last ten years. I say this because of all the statements we made in our original 2009 proclamation, the one that sounds the most hollow in retrospect is that 'The question of 'the next new technology' (meaning digital) is really only of interest to venture capitalists and pundits looking to secure their future funding.' (52group 2009)

The experience of many people working in higher education now is that it's not just venture capitalists and pundits who needed to predict the next new technology in 2009; it's academics and support staff too (if they happen to be working in the field of the use of technology in education). Dave White's 2015 observation that 'practice evolves at a much slower pace than technology' and 'institutions incorporate the 'new' only to serve what they already understand' (White 2015) are both very much in evidence still, but in their desire to incorporate the technologies that are seen to do that serving, they naturally draw on those who have experience with those technologies. Reductions in funding for research, and in the recruitment of staff, means that over the past five years it has become even more important to have researched and published about the educational platforms, technologies, movements that everyone uses, but don't use them so much that they've stopped noticing them. At the moment, those are probably Open Educational Resources and MOOCs, but that could soon be changing.

In this context, therefore, the 'right' technologies to have backed are the ones that have succeeded enough to be wanted by universities, but not so much that they've become incorporated into normal practice; the middle ground in the postdigital movement. 'Videoconferencing co-ordinator' is not a role with long-term career prospects, because anyone can Skype. Screencasting is similarly something anyone is expected to do and, sooner rather than later, the people marking up the content to go into the VLE will go the way of the typing pool.

At the other end of the spectrum, how are all those AI tutors coming along? That virtual world campus? 3D printing? There may be research bubbling away at the peripheries, but anyone trying to build a career in supporting their growth in teaching is going to be struggling at the moment. Perhaps now is the time to be getting into them, because they will be The Next Big Thing, but at the moment I doubt it.

However, let's meet up again in another ten years and we can all look at how wrong I was.

\section{Postdigital: 10 years later, algorithms and agency (Lawrie Phipps, 17 April 2019)}

In 'Preparing for the postdigital era' (52group 2009) we, the authors, were looking to articulate how technology is not a driver of social change, but an enabler. In original article in 2009 we tried to articulate the subsuming of technology into society so that its presence, and to some extent the continued proliferation and innovation becomes a social and cultural norm. 'Not only is the digital subservient to the social, it is, in some ways (and soon most ways), 
transparent. We are moving towards a postdigital age where the tools driven by the microprocessor are common to the extent to which they will no longer be noticed.' (52group 2009)

At the time I was thinking about digital moving from being novel or innovative to being seen as 'the norm', being seen as just something we do. Therefore, my working definition of 'postdigital' was an environment where digital was embedded and invisible.

Since working with colleagues on that 'Preparing for the postdigital era' (52group 2009) paper my focus has been centred on education practices and how some individuals have been enabled to change or modify their own practices to teach or research more effectively. Many of the changes have been positive for those of us privileged enough to work in the education sector. Observing through the lens of social media, for example, individuals being able to instantly access a wide network to test ideas and discuss them. There is a growing group of academics and academic related staff that can be identified and recognised through the online promotion and increased visibility of their work and their participation in network activities. The way they interact and collaborate through social media and connect their various networks on different platforms is also distinctive.

This networked behaviour does feels indicative of a positive postdigital paradigm. In 2015, we re-visited our notions of postdigital, and at that point, I was thinking about digital in terms of people's relationships with their institutions, and how those connections had become more fluid and agile thanks to the affordances of digital. So that working definition of postdigital was about networks, and behaviours of individuals within the network, as combinations of their data, the technology and tools they use, and their culture values and behaviours interacted (Figure 1).

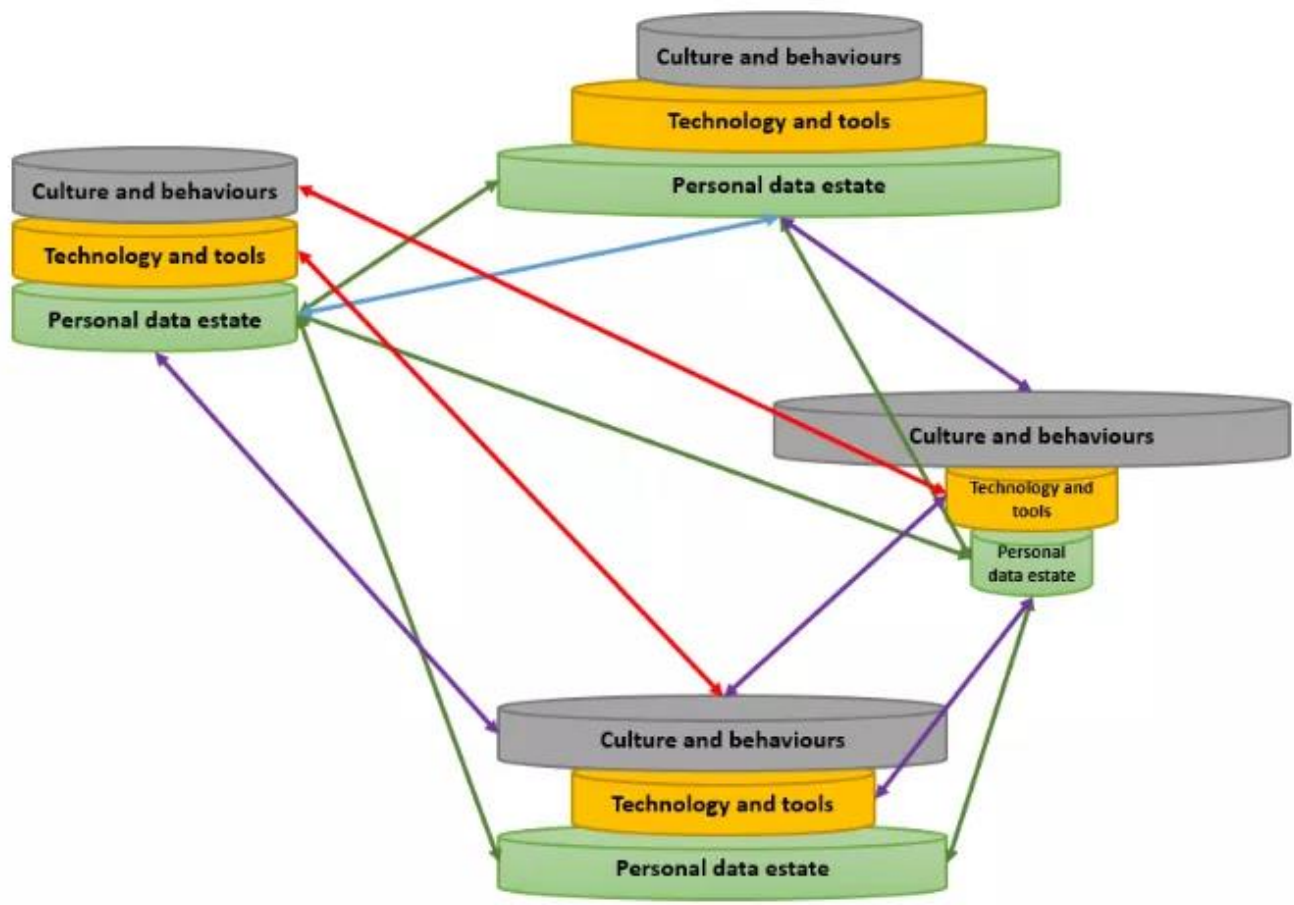

Figure 1: Postdigital networks connect on different layers. 
Moving within an academic institutional postdigital ecosystem, we can see how each of the actors within an institution interacts on these three layers, and with the corresponding institutional layers; the data estate, the technology and tools available, and their behaviours within the institutional culture. However, the individuals are networked well beyond the boundaries of their institutions, the thriving postdigital ecosystem will account for and celebrate the networked possibilities that may bring in outside influences to innovate and change, and also contribute to the wider postdigital academy.

In our recent research, published in Irish Journal of Technology Enhanced Learning Donna Lanclos and I highlighted issues of trust, risk and innovation within institutional teaching and learning contexts (Phipps and Lanclos 2019). These three areas are good examples that would fit in the 'culture and behaviour' layer in the model above. But these are also prime examples that impact on technology, tools and data layers.

When trying to influence or change something as complex as a digital ecosystem, it is essential that we have an understanding of all of the factors in play. Techno-centrists and tech evangelists will always talk of the positive impact of introducing a new tool, but little thought is given to negative or long-term impacts. The mantra with implementing technology in Silicon Valley is fail fast, fail often. We see this narrative creeping into EdTech, and we even see it repeated by senior managers in the education sector (read Audrey Watters). But there is no evidence to support this approach. And whilst we talk about the long tail of impact of projects that have been built in years past, who is talking about the long tail of failure. Would the sector have been so fast to sign up to a plagiarism service 10 years ago, if they had known all the student IP would one day be the property of a publishing company?

Go to any large organisation and there will be an attitude of 'them or they', that is to say that even in senior managers there is often an unconscious reaction to some changes; we refer to the organisation as if it were conscious. 'We need to do $x$ ?' is sometimes initially met with 'The institution won't let us' or even a department. 'We should do y' is met with 'the faculty of z won't like it'. Similarly, we give agency to digital, talking about how it does things, when in fact it's been built by people to do those things.

This was, to me, an unexpected facet of the postdigital from the way we first envisaged it: the way we talk about these systems, these tools, these algorithms, as if they are entitled with agency, thus absolving those who control them of responsibility. This is dystopian postdigital, where users feel they must use the systems to be able to live their lives, even as they recognise the surveillance (read Chris Gilliard) and tracking, political bias (read Safiya Noble) and prevalence of bots and trolls. We walk towards it with (sometimes) resistance and reluctance, but still we move toward it.

The naive utopia we described in our 2009 postdigital paper probably only exists in the minds of idealists and tech evangelists. People have designed digital tools, platforms, and other environments with political and financial motives. In our current postdigital world, digital does not serve the social, but through the manipulation of people, it is driving a particular kind of society, one that exploits the weaknesses and and fears of people; enables the rise of racism and xenophobia, and intensifies inequality.

The postdigital we described in 2009 must not become a reality. Digital must not disappear into use, become invisible. An effective postdigital society must be one where we spend time and energy ensuring that digital is not only seen as present, but also explicitly and critically noticed. For me the postdigital we got is the opposite of what we originally tried to define. Postdigital now must involve monitoring the algorithms, and those people who have the power to manipulate digital to exploit others. 


\section{What Have We Learned During the Past Eleven Years? (Petar Jandrić, 22 April 2019)}

As I begin to write these words, I feel like a stranger, an intruder, an uninvited guest who crashed her elder siblings' party. During the past 11 years, while members of the 52 group have been periodically meeting and reflecting upon our postdigital reality, I went through a series of jobs from learning technologist at the Glasgow School of Art through zero-hourscontract lecturer at the University of East London to full professorship at Zagreb University of Applied Sciences - with a few more jobs in between. While I was learning what it means to do research and to be an academic, members of the 52group have produced sophisticated insights that I was to discover only years later. And yet, during all that time, we have been in the same boat - implementing the same (educational) technologies and dealing with the same consequences. As I founded the Postdigital Science and Education journal, these different paths have converged in our shared interest in the postdigital. When Gordon Asher emailed me links to 'Preparing for the postdigital era' (52group 2009) and some of the 2015 responses, I emailed Dave Cormier in search for some intellectual ancestry.

52 group's reflections present a rich tapestry of opinions and feelings about our postdigital reality. The authors warn that the 52group is all white, male, and privileged; analyse the disappearing of the digital into use; critique their early thinking as overly technodeterminist and / or optimistic; talk about their children (some of whom are now fully grown up, voting-age people!); describe challenges pertaining to dealing with jerks; question existing social contracts and call for developing new ones. Many of these themes are reflected in recent academic articles such as 'Critical Philosophy of the Postdigital' (Peters and Besley 2019), 'Pedagogy of the 'Not': Negation, Exodus, and Postdigital Temporal Regimes' (Ford 2019), 'Postdigital Education in Design and Practice' (Fawns 2019), 'Between the Post and the Com-Post: Examining the Postdigital 'Work' of a Prefix' (Sinclair and Hayes 2019) (to mention just a few), and addressed more specifically in two recent reflection papers (Jandrić et al. 2018, Arndt et al. 2019). After several years of researching and supporting research in and around the postdigital, I am happy to see so much convergence between insights of the 52group and the budding community gathered around Postdigital Science and Education. In a way, the intended mission of this article is accomplished: our recent research efforts have now acquired some ancestry and direction for future work.

However, ancestors do not only pass on their knowledge to their successors; they also situate our present efforts into a larger historical framework and provide a sense of continuity. This article presents 11 years of development in thinking of six profound thinkers. The 2009 position paper is moderately optimistic, the 2015 reflections exhibit the first seeds of serious doubt, and the 2019 responses speak of lost ideals and grievances over missed opportunities. It is now clear that we need to give less attention to novelty, which is always bound for banal disappearance into use; put much more emphasis on negative aspects of the postdigital; monitor algorithms; recognise digitally reinforced flows of power and privilege; open up political structures for refusing techno-fuelled colonisation; identify the people beyond the technology; and focus on systemic cultural practices which shape us. While this important piece does provide profound insights into the nature of our postdigital reality, its most valuable contribution - in my opinion - is its unique insight into the evolution of feelings of people who have thought deeply about the postdigital era. My own journey to the postdigital has followed a very similar path from optimism to despair and, depending on the day, any 
point in between. It is amazing to see that I am not alone in this whirlwind of feelings, and it is even more amazing to see how insights of the 52group, taken together, articulate these feelings into a program of research and action. The postdigital should not be glorified, demonized, or taken for granted - it should be analysed and criticized, but also touched and smelled. The postdigital cannot be thought of without capitalism and neoliberalism. The postdigital is much more than an academic exercise - it questions how we feel about our reality. The postdigital is our present condition and our battlefield for the future. Paraphrasing Heidegger's famous adage, 'the essence of technology is by no means anything technological' (1977:4), the essence of the postdigital is by no means anything digital.

In academic publications, the term postdigital was first mentioned in Kim Cascone's article 'The aesthetics of failure: 'post-digital' tendencies in contemporary computer music' (Cascone 2000). One decade later, the 52group has published 'Preparing for the postdigital era' (52group 2009). One more decade later, we now have a new academic journal Postdigital Science and Education. In one of my favourite quotes in our 'mission statement' article for the journal, our editorial group wrote:

The postdigital is hard to define; messy; unpredictable; digital and analog; technological and non-technological; biological and informational. The postdigital is both a rupture in our existing theories and their continuation. However, such messiness seems to be inherent to the contemporary human condition. (Jandrić et al. 2019: 895)

We have all, in our own ways, contributed to the making of this postdigital mess. Now, we need to make at least some sense out of it. We struggle between ruptures and continuations of our theories and feelings. We start to realize which lessons should be taken forward and which lessons should be left to the past. Situated at the end of the end of history, we are now at the new beginning. With this conclusion, I no longer feel like an uninvited guest at my elder siblings' party. Seeking ancestors, I found fellow travellers - and I look forward to making the postdigital road by walking together.

\section{Open Review 1: Title (Sarah Hayes)}

Anyone seeking to learn more about their origins and ancestry risks discovering uncomfortable, as well as exciting, connections. What they find may cause them to think more deeply about their own identity, as they confront new information about their background and relations. Perhaps this experience will even change how they discuss what has gone before. The 52group describe in 2009, their 'attempt to negotiate a shared language and vision for future work'. At this point they were mainly looking ahead, not back, but their postdigital journeys become all the richer as they step reflexively back and forth across time periods, occasionally pausing to question dominant forms of language.

Each person does more than simply map their digital family tree. They critically confront their thinking and beliefs, for others to read. I found myself recalling points when I have talked with some of these authors, heard them present at events, or presented to them. Just as new digital platforms can enable an immersive experience, textual encounters can powerfully submerge us into a plot. These authors have succeeded in immersing me into their past and present, along with the skeletons in the closet they unearthed. 
I wonder though, if it is a story with a recurring, often deceptive plot, where the names we attach to human practices with technology continually distance us as humans from more critical understandings. Yet if we do turn around we can discover an even longer intellectual ancestral line. One that, as Petar comments, might 'situate our present efforts into a larger historical framework'.

Whilst researching for my $\mathrm{PhD}$, I came across a rather wonderful edited publication from 1991 called: Paradigms Regained: the uses of Illuminative, Semiotic and Post-Modern Criticism as Modes of Inquiry in Educational Technology (Hlynka and Belland 1991). These authors suggested that even in 1991, educational technology was lagging behind other fields and disciplines, having become 'stuck fast in a technological means-end model which goes by a variety of names' (Hlynka and Belland 1991). Just as a plot needs investigating, we need to not only interrogate the 'variety of names' we apply to technology, but the embedded human agency we often attribute to it. In 1991 Hlynka and Belland argued that the paradigm of critical theory had been largely ignored in educational technology. Nearly 20 years on, we can reflect on whether this has changed.

As I share the 52group's confrontation of former and current beliefs regarding the digital, I notice further references to language. Just as for Hlynka and Belland, for me, this digital journey has always concerned an ongoing resistance to deterministic forms of language, particularly as these are expressed and repeated across university policies about technology and learning. The 52group acknowledge that 'the postdigital frees us to think more clearly and precisely about the issues we face, rather than become tied to an obsession with, and the language of, the new'. I have to agree. The postdigital offers a potential space for critical dialogue about socio-technical matters and learning, away from a tired rhetoric of assumed enhancement. A perpetual focus on the 'new' in policy for technology has unfortunately drawn attention away from many ongoing inequalities in education.

As I read on, I find further references to the role of discourse in shaping myths about the digital: 'Postdigital aims to throw off the yoke of digital dogma, where the language of a perceived digital elite drives not only development, but also skews innovation, where innovation is only seen as being that associated with the 'latest' technology'. This suggests that we might yet re-imagine a more empowering form of human innovation, not as 'driven' by the digital (as if technology were able to 'act' independently of humans), or as apart from the digital. Instead, as Tim Fawns puts it, with the digital 'integrated into our complex ecologies'. There are real dangers if we do not. Towards the end of their journey, these authors stumbled on 'an unexpected facet of the postdigital' that was different from 'the way we first envisaged it - the way we talk about systems as if they are entitled with agency, absolving those who control them of responsibility'. This indeed is the recurring, deceptive plot that policy for the digital in education has extensively and globally reinforced. There is an urgency now to completely reject the notion that technology (or language) act alone. We can then move on to immerse ourselves in what collective, critical re-imaginings for the postdigital might offer.

\section{Open Review 2: Title (Tim Fawns)}

In 2009, six people see the disappearance of the digital in use as a prescription for the intolerable tedium of continuous novelty. In 2015, they sound notes of alarm: digital technology did not really disappear, it just became hidden amongst the social, political, economic and cultural. The postdigital reality they sought has leeched irreversibly into their 
bloodstreams, and is developing into troubling side effects. In 2019, they have reached some stark conclusions. Problems have become pervasive, and a battle is needed to save society from breakdown. Mild hope is attached to forms of academic resistance, but, recognising that we must find ways to live with our postdigital condition, the authors hint at dreams of a reality untouched by insidious digital effects.

There is, however, an alternative reading of the 2009 paper. Rather than a disappearance, 'postdigital' can be a clarity of vision; a way of seeing past the glint and gleam, to the entanglement of the digital in social and material structures.

From this alternative postdigital view, new is distinguished from repackaged old. Novelty is not shininess, but the (decreasing) protrusion of something new from the ecology below, before it submerges into its context. In searching for ancestry, Petar Jandrić understandably gives 'less attention to novelty,' instead, looking for digital roots that have become tangled with other elements, creating effects just as material as the hardware through which zeros and ones manifest in real and virtual forms. Yet it is familiarity and ubiquity potential opposites of novelty - that allow technologies to fade into the everyday, despite their intrusive, shaping influence. Novelty, in contrast, draws attention. If we use this heightened attention to look past instrumental qualities (functionality, efficiency gains, etc.) to how technology is integrated into complex ecologies, then we can ask new questions and, perhaps more importantly, old questions we forgot to ask before.

I agree that we must also move beyond novelty. When technology disappears in use, we need ways of seeing the transparent, and of seeing through the opaque datafication of ingrained social processes. Some of the authors come to similar conclusions, but where they see postdigital as the problem, I see it as a useful critical perspective. When the workings and entanglements of the digital are visible, it's clear that we do not want 'just stuff that works' but ways of embedding technology while minimising harm. And we can see that 2009 was not, in fact, the ideal time for this concept to emerge. It has been relevant since the invention of digital technology.

In this challenging decade, technologies have been weaponized and used to introduce forms of corruption throughout society. But digital technology has also been used to promote healthy social connections, and to resist capitalist and neoliberal agendas. The authors are rightly concerned, but their later accounts betray hints of the instrumentalism they cautioned against in 2009. Clearly, we need what Sarah Hayes calls an 'ongoing resistance to deterministic forms of language' that so easily creep back into thinking and writing. A critical postdigital perspective, in which the digital can be seen as part (and, crucially, not apart) of the fabric of everyday life, can protect against rigid views of the qualities and effects of technology. That perspective is buried in the original article, waiting to be excavated, reinvigorated and carried forward to help us resist, not only the authors' digital despair, but also the troubling trends that have given rise to it.

\section{Acknowledgements}

Petar Jandrić would like to thank Gordon Asher for introducing him to writings of the 52 group and for thoughtful discussions which inspired development of this article.

\section{References}


52group (2009). Preparing for the postdigital era - Version 0.1 June 17th, 2009. https://docs.google.com/document/d/1TkCUCisefPgrcG317_hZa4PwZoQ8m7rL5AJF6PazH $\mathrm{HQ} /$ preview?pli=1. Accessed 15 April 2019.

Arndt, S., Asher, G., Knox, J., Ford, D. R., Hayes, S., Lăzăroiu, G., Jackson, L., Mañero Contreras, J., Buchanan, R., D’Olimpio, L., Smith, M., Suoranta, J., Pyyhtinen, O., Ryberg, T., Davidsen, J., Steketee, A., Mihăilă, R., Stewart, G., Dawson, M., Sinclair, C., \& Peters, M. A. (2019). Between the Blabbering Noise of Individuals or the Silent Dialogue of Many: a Collective Response to 'Postdigital Science and Education' (Jandrić et al. 2018). Postdigital Science and Education. https://doi.org/10.1007/s42438-019-00037-y.

CASA (2015). CASA: Casual, Adjunct, Sessional staff and Allies in Australian Higher Education. https://actualcasuals.wordpress.com/casa/. Accessed 15 April 2019.

Cascone, K. (2000). The aesthetics of failure: 'post-digital' tendencies in contemporary computer music. Computer Music Journal, 24(4), 12-18.10.1162/014892600559489.

Childs, M. (2015). Post-digitalism - an evolutionary perspective. 4 February. https://markchilds.org/2015/02/04/post-digitalism-an-evolutionary-perspective/. Accessed 15 April 2019.

Cormier, D. (2015). Looking back at 'postdigital' 6 years later. 6 February. http://davecormier.com/edblog/2015/02/06/looking-back-at-postdigital-6-years-later/.

Accessed 15 April 2019.

Cormier, D. (2019). The impact of conformity in education. 27 February. http://davecormier.com/edblog/2019/02/27/the-impact-of-conformity-on-education/. Accessed 15 April 2019.

Cornish, E. (2004) Futuring: The Exploration of the Future. Bethesda (U.S.): World Future Society.

Davies, W. (2014). The Limits of Neoliberalism: Authority, Sovereignty and the Logic of Competition. London: SAGE.

Fawns, T. (2019). Postdigital education in design and practice. Postdigital Science and Education, 1(1), 132-145. https://doi.org/10.1007/s42438-018-0021-8.

Ford, D. R. (2019). Pedagogy of the "not:" negation, exodus, and postdigital temporal regimes. Postdigital Science and Education, 1(1), 104-118. https://doi.org/10.1007/s42438018-0009-4.

Forster, E. M. (1909). The Machine Stops. Oxford and Cambridge Review, November. https://www.ele.uri.edu/faculty/vetter/Other-stuff/The-Machine-Stops.pdf. Accessed 15 April 2019.

Gartner. (2013). Gartner reveals top predictions for IT organizations and users for 2014 and beyond. https://www.gartner.com/en/newsroom. Accessed 15 April 2019.

Hall, R. (2014a). Notes on the University as anxiety machine. 10 July. http://www.richardhall.org/2014/07/10/notes-on-the-university-as-anxiety-machine/. Accessed 15 April 2019.

Hall, R. (2014b). On mutual values and open co-operativism. 19 June. http://www.richardhall.org/2014/06/19/on-mutual-values-and-open-co-operativism/. Accessed 15 April 2019.

Hall, R. (2019). Education, technology and the end of the end of history. 3 April. http://www.richard-hall.org/2019/04/03/education-technology-and-the-end-of-the-end-of-

history/. Accessed 20 April 2019.

Haraway, D. (1991) [1985]. Simians, cyborgs, and women: The reinvention of nature. New York: Routledge.

Heidegger, M. (1977). The Question Concerning Technology. New York and Toronto: Harper \& Row. 
Howe, N. (2017). Millennials: a Generation of Page-Turners. The Forbes, 16 January. https://www.forbes.com/sites/neilhowe/2017/01/16/millennials-a-generation-of-pageturners/\#680b66ff1978. Accessed 15 April 2019.

Hylnka, D., \& Belland, J. C. (Eds.) (1991). Paradigms Regained: the uses of Illuminative, Semiotic and Post-Modern Criticism as Modes of Inquiry in Educational Technology. Englewood Cliffs, NJ: Educational Technology Pubns.

Jandrić, P., Knox, J., Besley, T., Ryberg, T., Suoranta, J., \& Hayes, S. (2018a). Postdigital science and education. Educational Philosophy and Theory, 50(10), 893899. https://doi.org/10.1080/00131857.2018.1454000.

Kluszczyński, R. W. (2014). Meat, Metal \& Code / Contestable Chimeras STELARC. Laznia: Laznia Centre for Contemporary Art.

Marx, K. (1844). Private Property and Communism. https://www.marxists.org/archive/marx/works/1844/manuscripts/comm.htm. Accessed 15 April 2019.

Marx, K., \& Engels, F. (1976/1848). The Communist Manifesto. https://www.marxists.org/archive/marx/works/1848/communist-manifesto/ch01.htm.

Accessed 15 April 2019.

Pasek, A. (2015). Errant Bodies: Relational Aesthetics, Digital Communication, and the Autistic Analogy. Disability Studies Quarterly, 35 (4). http://dx.doi.org/10.18061/dsq.v35i4. Balsamo, A. (1995). Technologies of the Gendered Body: Reading Cyborg Women. Durham, NC: Duke University Press.

Peters, M. A., \& Besley, T. (2018). Critical philosophy of the postdigital. Postdigital Science and Education, 1(1), 29-42. https://doi.org/10.1007/s42438-018-0004-9.

Phipps, L. (2015). Reviewing the Post-digital. 6 February. http://lawriephipps.co.uk/?p=391. Accessed 15 April 2019.

Phipps, L. (2019). Postdigital: 10 years later, Algorithms and Agency. 17 April. http://lawriephipps.co.uk/?p=9267. Accessed 20 April 2019.

Phipps, L., \& Lancloss, D. (2019). Trust, innovation and risk: a contextual inquiry into teaching practices and the implications for the use of technology. Irish Journal of Technology Enhanced Learning, 4,(1), 68-85.

Porter, J. (2019). Vinyl and cassette sales saw double digit growth last year. The Verge, 6 January. https://www.theverge.com/2019/1/6/18170624/vinyl-cassette-popularity-revival2018-sales-growth-cd-decline. Accessed 15 April 2019.

Prensky, M. (2001). Digital natives, digital immigrants. On the Horizon, 9(5).

Richmond, R. (2014). Unpaid Trials \& Self-Exploiting Entrepreneurs. The Occupied Times of London, 6 September. http://theoccupiedtimes.org/?p=13436. Accessed 15 April 2019.

Saccaro, M. (2014). Professors on food stamps: The shocking true story of academia in 2014. Salon, 21

September. https://www.salon.com/2014/09/21/professors_on_food_stamps_the_shocking_true_story_of _academia_in_2014/. Accessed 15 April 2019.

Schultz, R. (2018). SL Infographic: Some Statistics from 15 Years of SL. https://ryanschultz.com/2018/04/23/second-life-infographic-some-statistics-from-15-years/.

Accessed 20 April 2019.

Sinclair, C., \& Hayes, S. (2019). Between the post and the com-post: examining the postdigital 'work' of a prefix. Postdigital Science and Education, 1(1), 119131. https://doi.org/10.1007/s42438-018-0017-4. 
Staff and Educational Development Association (2014). 19th Annual SEDA Conference: Opportunities and challenges for academic development in a post-digital age. https://www.seda.ac.uk/events/info/450. Accessed 15 April 2019.

The 3 Cosas Campaign (2019). About. https://3cosascampaign.wordpress.com/about/. Accessed 15 April 2019.

Turkle, S. (1997). Life on the Screen: Identity in the Age of the Internet. New York: Simon \& Schuster.

Turkle, S. (2012). Alone together: Why we expect more from technology and less from each other. New York: Basic Books.

University of Greenwich (2015). The Academic Practice and Technology (APT) Conference 2015: Flipping the Institution: Higher Education in the Post Digital Age. https://showtime.gre.ac.uk/index.php/ecentre/apt2015/schedConf/index. Accessed 15 April 2019.

White, D. (2014). Postdigital: Escaping the Kingdom of the New? 19 June. http://daveowhite.com/postdigital-escaping-the-kingdom-of-the-new/. Accessed 15 April 2019.

White, D. (2015). Post-digital revisited. 19 June. http://daveowhite.com/2015/02/. Accessed 15 April 2019.

White, D. (2019). Too postdigital. 12 April. http://daveowhite.com/too-postdigital/. Accessed 15 April 2019. 